\title{
Synthesis and in vitro studies of a Gd(DOTA)-porphyrin conjugate for combined MRI and photodynamic treatment
}

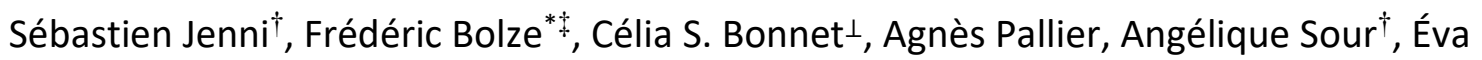 \\ Tóth $^{*} \perp$, Barbara Ventura* ${ }^{*}$ and Valérie Heitz ${ }^{* \dagger}$ \\ † Laboratoire de Synthèse des Assemblages Moléculaires Multifonctionnels, Institut de Chimie de \\ Strasbourg, CNRS/UMR 7177, Université de Strasbourg, 4 rue Blaise Pascal, 67000 Strasbourg, \\ France \\ † CAMB, UMR 7199, Unistra/CNRS, Faculté de Pharmacie, Université de Strasbourg, 74 route du \\ Rhin, 67401 Illkirch, France \\ $\perp$ Centre de Biophysique Moléculaire, CNRS UPR 4301, Université d'Orléans, rue Charles Sadron, \\ CS 80054, 45071 Orléans Cedex 2, France \\ || Istituto ISOF-CNR, via P. Gobetti 101, 40129 Bologna, Italy
}

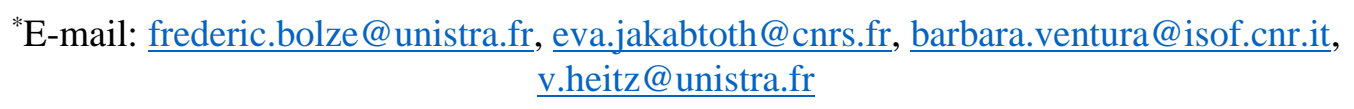

Table of Contents

Figure S 1. ${ }^{1} \mathrm{H}$ NMR $\left(\mathrm{CDCl}_{3} /\right.$ pyridine- $\left.\mathrm{d}_{5}{ }^{*}, 400 \mathrm{MHz}, 298 \mathrm{~K}\right)$ spectrum of DPP-ZnP- $\left(\mathrm{NH}_{2}\right)_{2} \ldots \ldots \ldots \ldots \ldots \ldots . . . . . . . . . . .2$

Figure S 2. ${ }^{13} \mathrm{C} \mathrm{NMR}\left(\mathrm{CDCl}_{3} /\right.$ pyridine- $\left.\mathrm{d}_{5}{ }^{*}, 125 \mathrm{MHz}, 298 \mathrm{~K}\right)$ spectrum of DPP-ZnP- $\left(\mathrm{NH}_{2}\right)_{2} \ldots \ldots \ldots \ldots \ldots \ldots . . . . . . . . . . .3$

Figure S 3. HR ES-MS of DPP-ZnP- $\left(\mathrm{NH}_{2}\right)_{2}$ and the corresponding calculated profile for $[\mathrm{M}+\mathrm{Na}]^{+} \ldots \ldots . . .4$

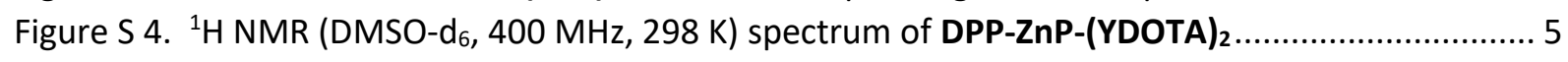

Figure S 5. HR ES-MS of DPP-ZnP-(YDOTA) $)_{2}$ and the corresponding calculated profile for $\left[\mathrm{M}-2 \mathrm{H}_{2} \mathrm{O}\right.$ -

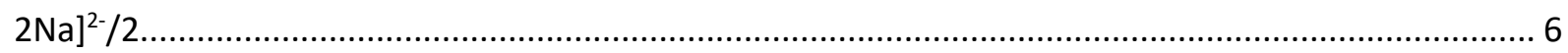

Figure S 6. HR ES-MS of DPP-ZnP-(GdDOTA $)_{2}$ and the corresponding calculated profile for $\left[\mathrm{M}-2 \mathrm{H}_{2} \mathrm{O}\right.$ -

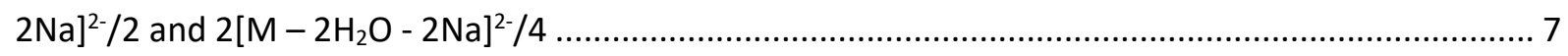

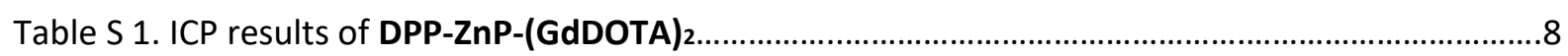

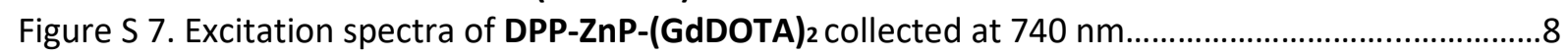

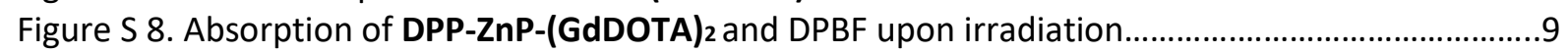

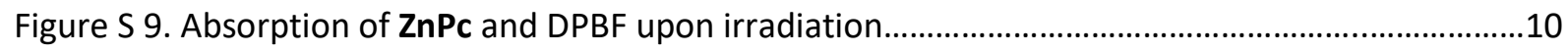

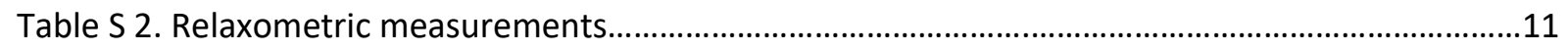



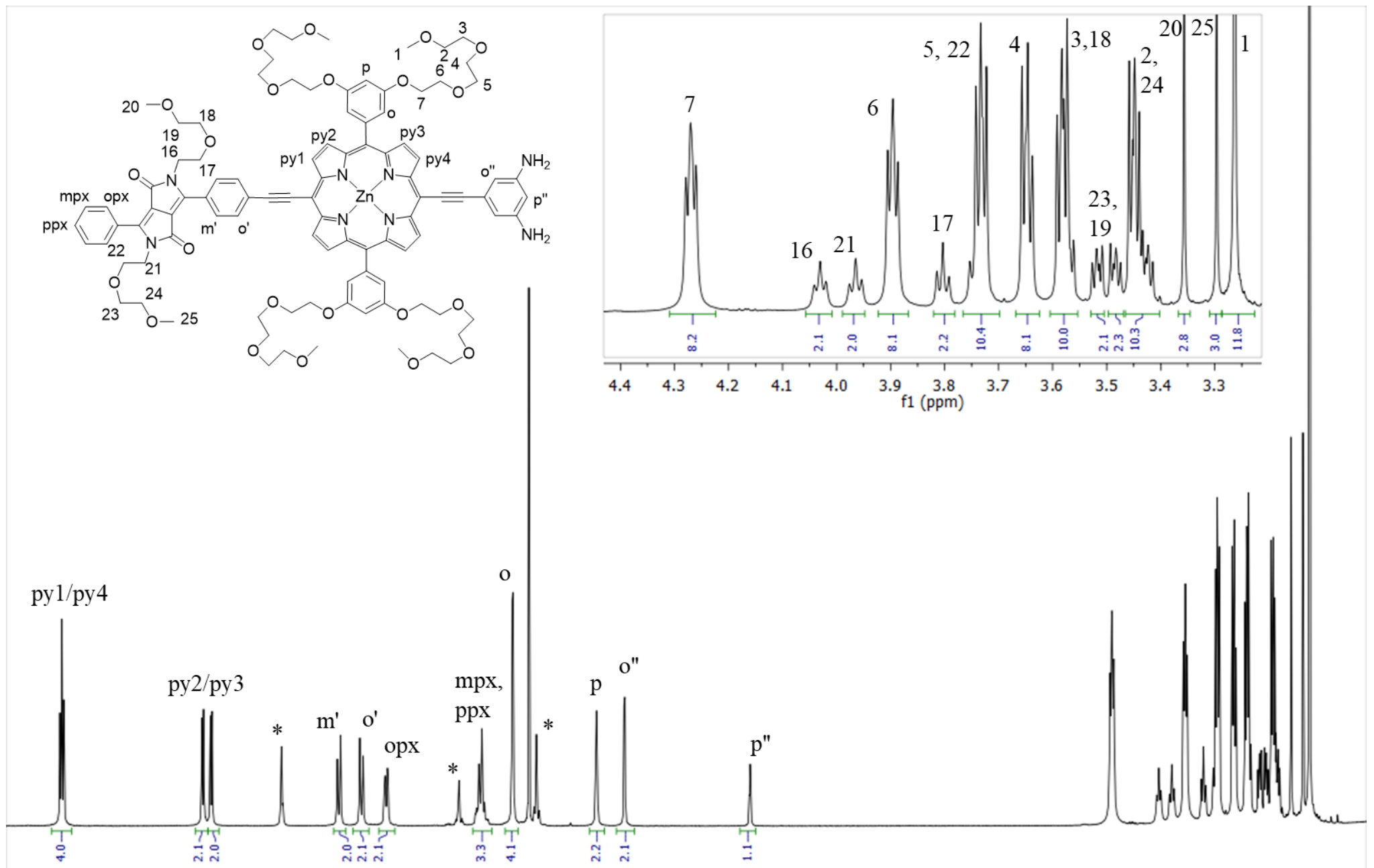

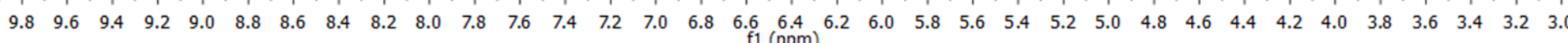
Figure S 1. ${ }^{1} \mathrm{H}$ NMR $\left(\mathrm{CDCl}_{3} /\right.$ pyridine- $\left.d_{5}{ }^{*}, 400 \mathrm{MHz}, 298 \mathrm{~K}\right)$ spectrum of DPP-ZnP- $\left(\mathrm{NH}_{2}\right)_{2}$ 


$$
\|
$$




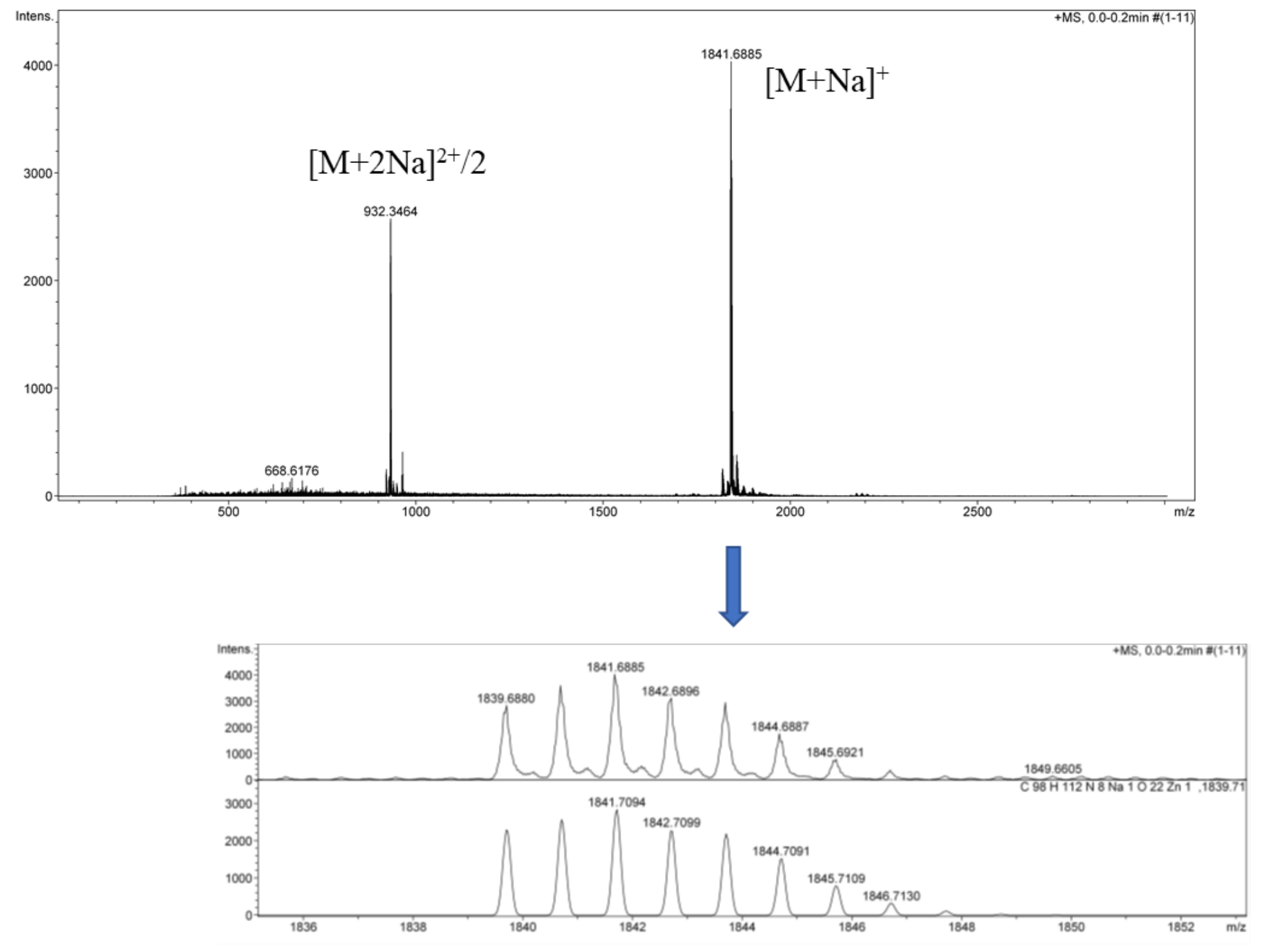

Figure S 3. HR ES-MS of DPP-ZnP- $\left(\mathrm{NH}_{2}\right)_{2}$ and the corresponding calculated profile for $[\mathrm{M}+\mathrm{Na}]^{+}$ 


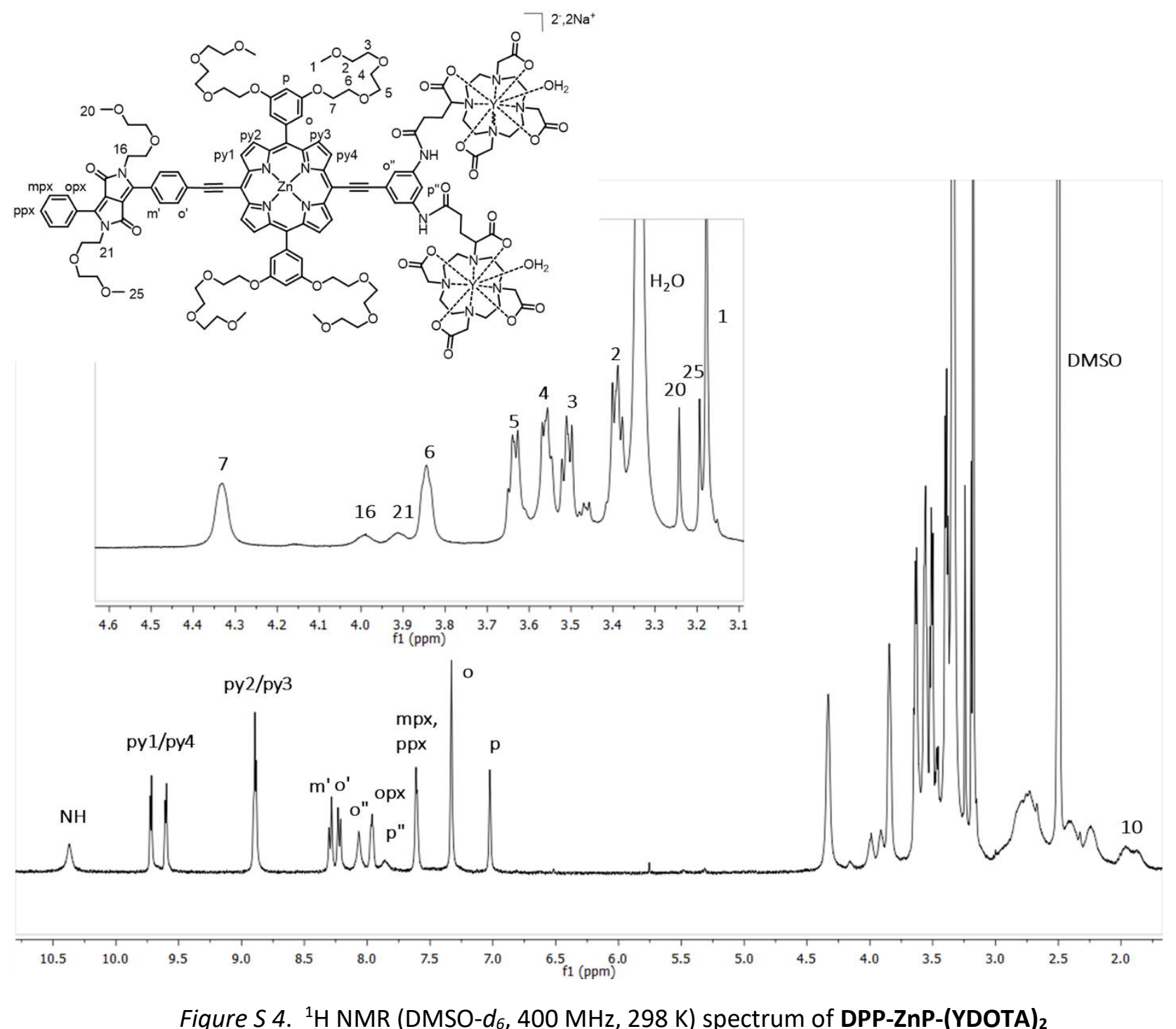




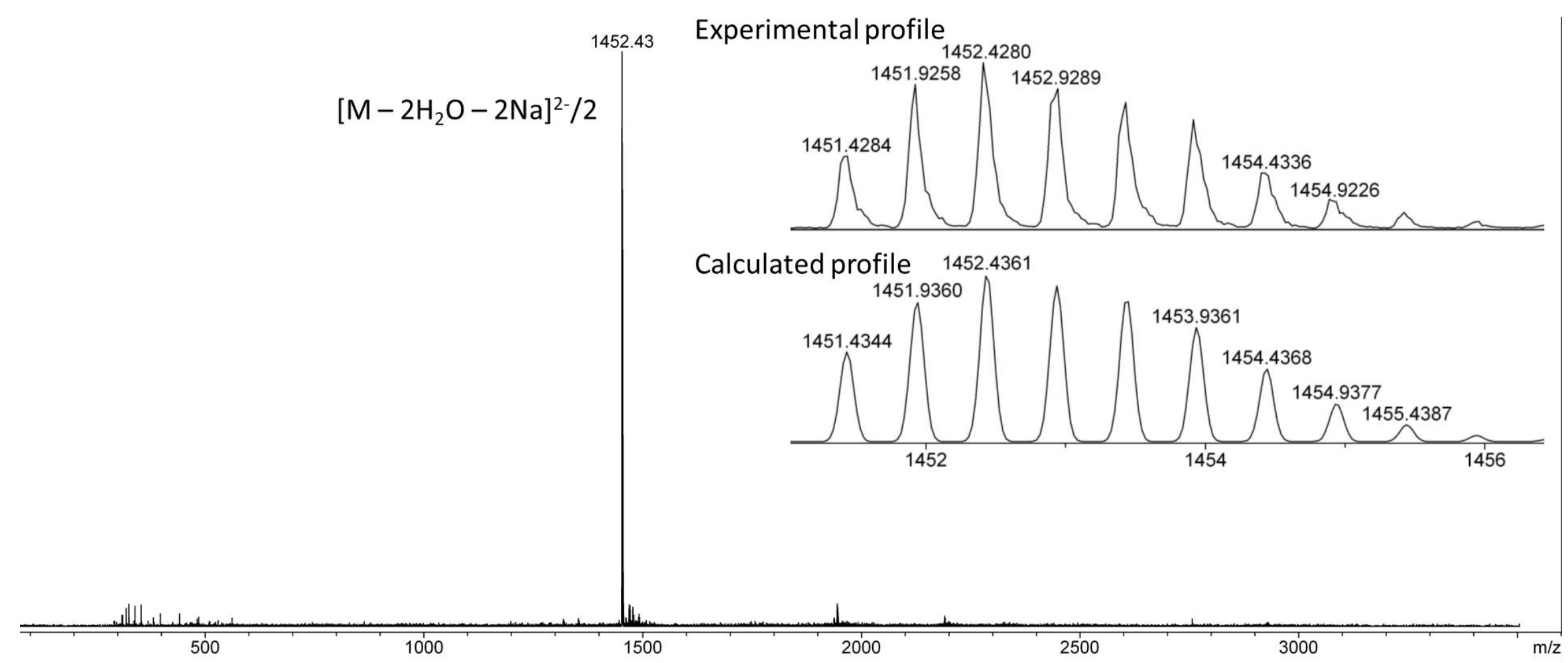

Figure S 5. HR ES-MS of DPP-ZnP-(YDOTA $)_{2}$ and the corresponding calculated profile for $\left[\mathrm{M}-2 \mathrm{H}_{2} \mathrm{O}-2 \mathrm{Na}\right]^{2-} / 2$ 


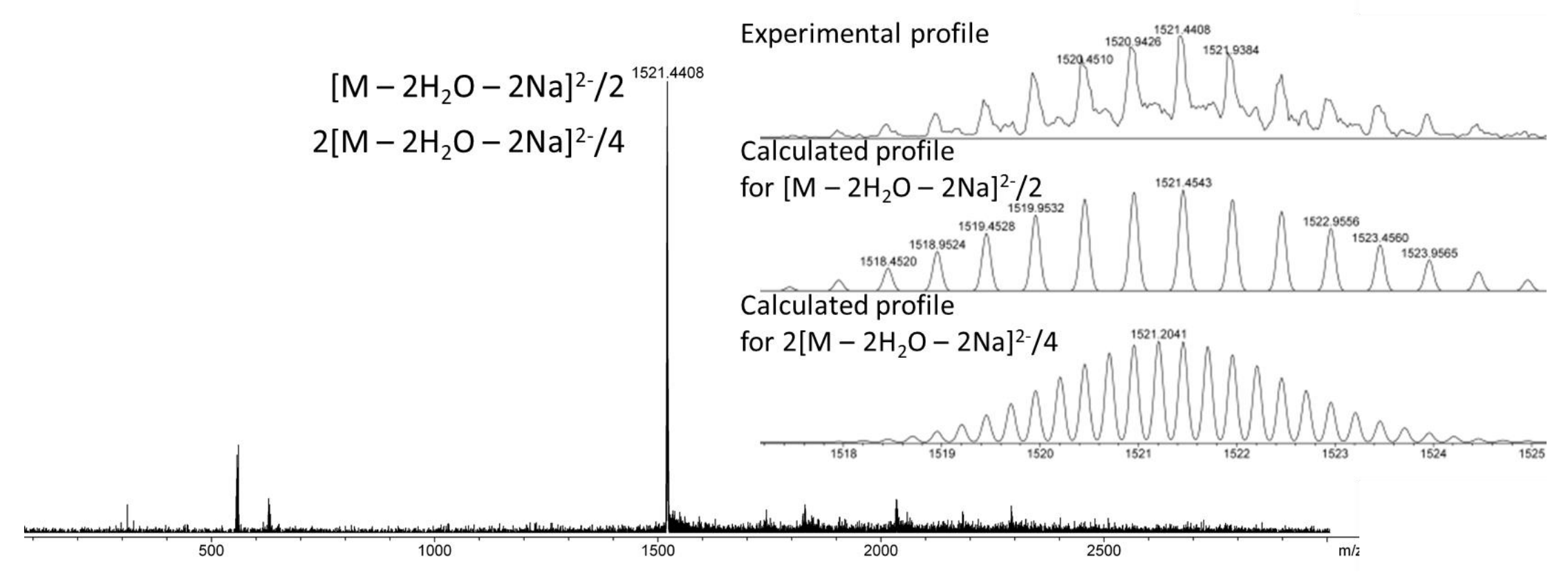

Figure S 6. HR ES-MS of DPP-ZnP-(GdDOTA $)_{2}$ and the corresponding calculated profile for $\left[\mathrm{M}-2 \mathrm{H}_{2} \mathrm{O}-2 \mathrm{Na}\right]^{2-} / 2$ and $2\left[\mathrm{M}-2 \mathrm{H}_{2} \mathrm{O}-2 \mathrm{Na}^{2-} / 4\right.$ 
Table S 1. ICP results of DPP-ZnP-(GdDOTA) 2 .

\begin{tabular}{lll}
\hline Compoud & $G d(\mathrm{mmol} / \mathrm{kg})$ & $\mathrm{Zn}(\mathrm{mmol} / \mathrm{kg})$ \\
\hline DPP-ZnP-(GdDOTA) ${ }_{2}$ & $1.1 \pm 0,1$ & $0.58 \pm 0,04$ \\
& & \\
\hline
\end{tabular}
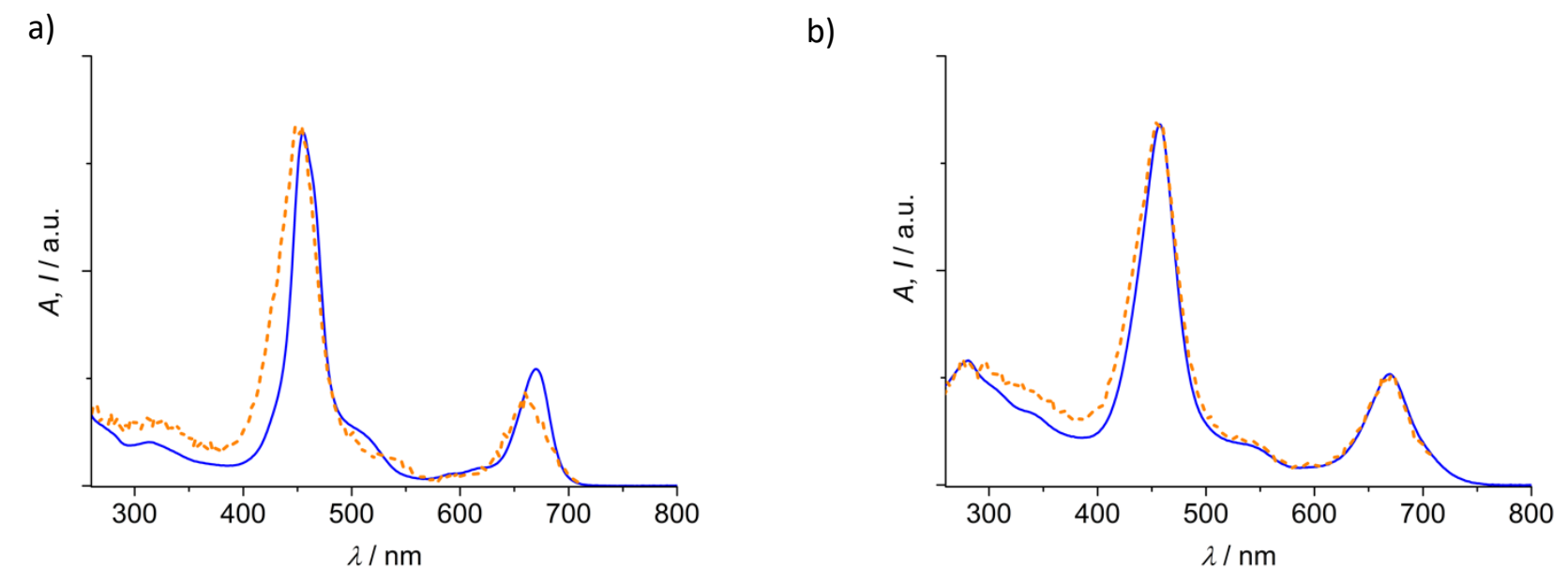

Figure S 7. Arbitrarily scaled excitation spectra collected at $740 \mathrm{~nm}$ (orange) and absorption spectra (blue) for DPP-ZnP-(GdDOTA) 2 in a) DMSO and b) $\mathrm{H}_{2} \mathrm{O}$. 

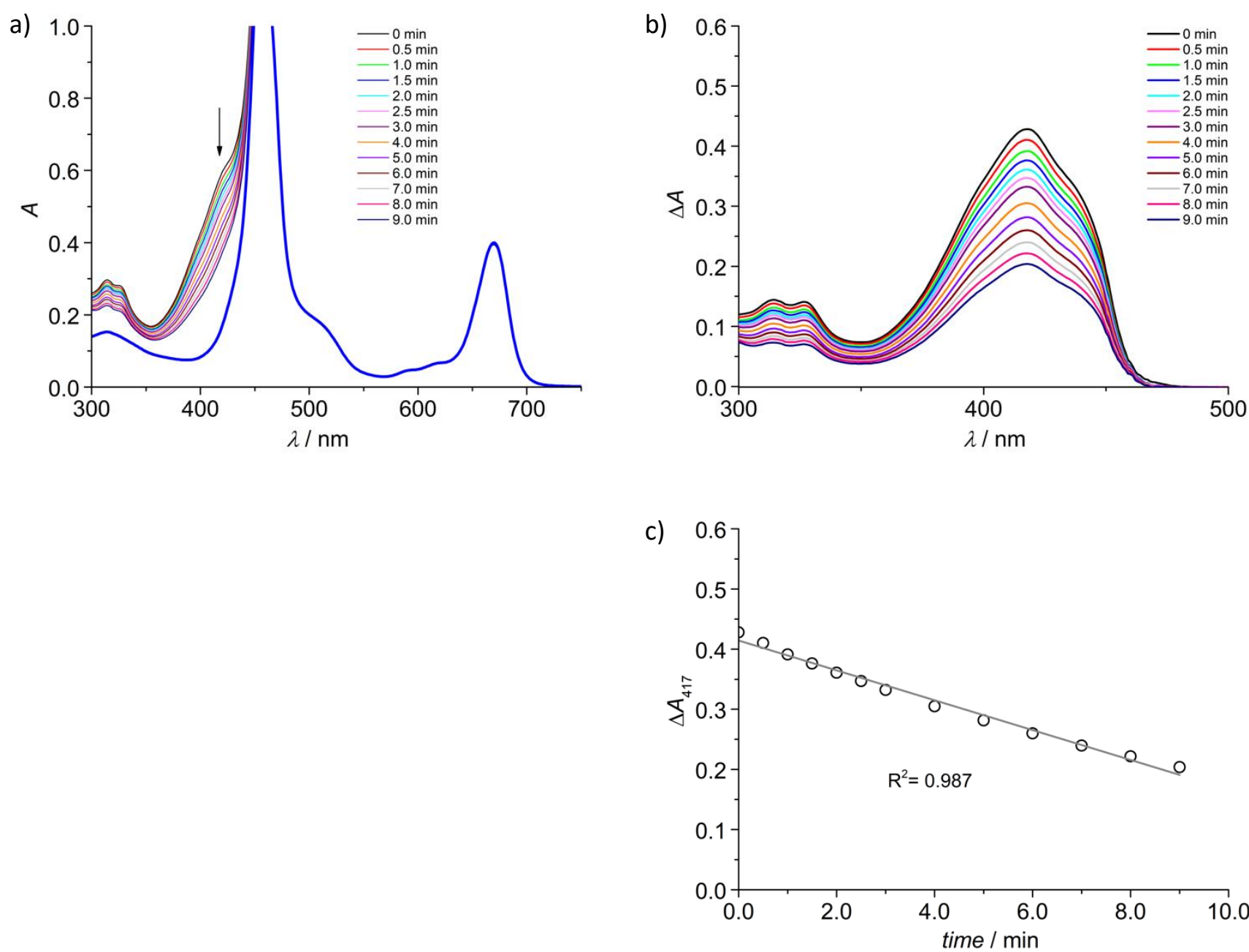

Figure S 8. a) Absorption spectra of a DMSO solution containing DPP-ZnP-(GdDOTA $)_{2}\left(6.8 \times 10^{-6} \mathrm{M}\right.$, blue thick) and DPBF $\left(2.0 \times 10^{-5} \mathrm{M}\right)$ upon irradiation at 672 $\mathrm{nm}(0-9 \mathrm{~min})$. b) The same spectra subtracted by the constant contribution of DPP-ZnP-(GdDOTA) 2 absorption. c) DPBF absorbance at $417 \mathrm{~nm}$ (open dots), from graph b), as a function of the irradiation time; the linear fitting is reported as a grey line. 

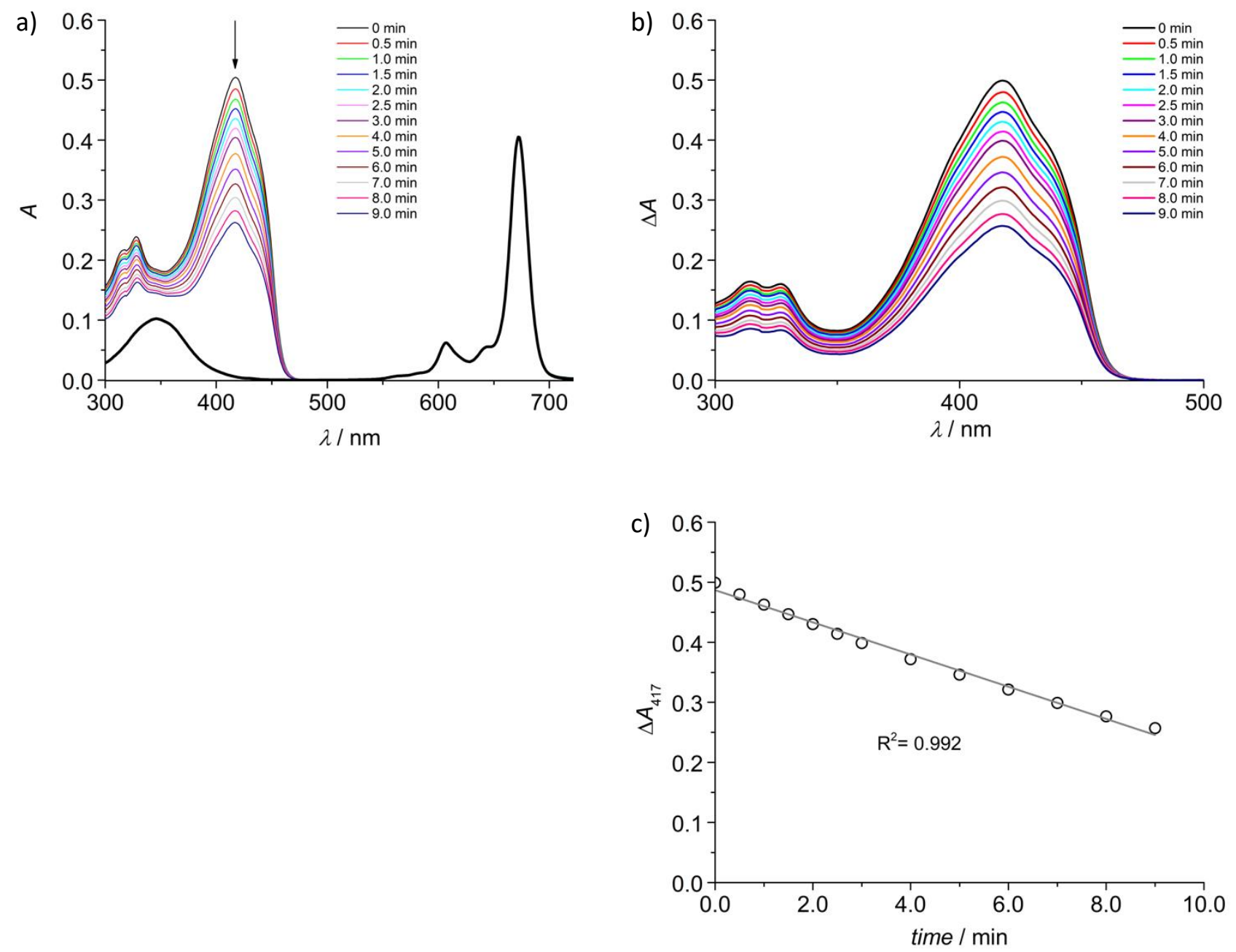

Figure S 9. a) Absorption spectra of a DMSO solution containing $\mathrm{ZnPc}\left(1.7 \times 10^{-6} \mathrm{M}\right.$, black thick) and DPBF $\left(2.2 \times 10^{-5} \mathrm{M}\right)$ upon irradiation at $672 \mathrm{~nm}(0-9 \mathrm{~min})$. b) The same spectra subtracted by the constant contribution of ZnPc absorption. c) DPBF absorbance at $417 \mathrm{~nm}$ (open dots), from graph b), as a function of the irradiation time; the linear fitting is reported as a grey line. 
Relaxometric measurements:

Table S2: Best fit parameters obtained from the fitting of the ${ }^{1} \mathrm{H}$ NMRD profile to the SBM theory, including the Lipari-Szabo approach for internal flexibility

\begin{tabular}{cc}
\hline Parameters & $\begin{array}{c}\text { DPP-ZnP-(GdDOTA })_{2} \text { in } \mathbf{H}_{2} \mathbf{O} \\
+\mathbf{1 \%} \text { DMSO }\end{array}$ \\
\hline$q^{a}$ & 1 \\
$k_{e x}^{298}\left(10^{6} \mathrm{~s}^{-1}\right)^{\mathrm{a}}$ & 4.1 \\
$\Delta \mathrm{H}^{\ddagger}\left(\mathrm{kJ}_{\mathrm{m}} \mathrm{mol}^{-1}\right)^{\mathrm{a}}$ & 49.8 \\
$E_{\mathrm{l}}\left(\mathrm{kJ} \cdot \mathrm{mol}^{-1}\right)$ & $21 \pm 6$ \\
$\tau_{l H}^{298}(\mathrm{ps})$ & $165 \pm 13$ \\
$E_{\mathrm{g}}\left(\mathrm{kJ} \cdot \mathrm{mol}^{-1}\right)$ & $19 \pm 5$ \\
$\tau_{g H}^{298}(\mathrm{ps})$ & $2250 \pm 250$ \\
$\mathrm{~S}^{2}$ & $0.30 \pm 0.03$ \\
$E_{\mathrm{V}}\left(\mathrm{kJ} . \mathrm{mol}^{-1}\right)^{\mathrm{a}}$ & 1 \\
$\tau_{V}^{298}(\mathrm{ps})$ & $49 \pm 8$ \\
$\Delta^{2}\left(10^{19} \mathrm{~s}^{-2}\right)$ & $0.04 \pm 0.01$ \\
\hline
\end{tabular}

a. Fixed during the fitting procedure 


\section{Equations used for the fitting of NMRD data, with the SBM model including the model-free Lipari-Szabo approach}

The measured longitudinal proton relaxation rate, $R_{1}^{o b s}=1 / T_{1}^{o b s}$, is the sum of a paramagnetic and a diamagnetic contribution as expressed in Equation (A1), where $r_{l}$ is the proton relaxivity:

$$
R_{1}^{o b s}=R_{1}^{d}+R_{1}^{p}=R_{1}^{d}+\mathrm{r}_{1}\left[\mathrm{Gd}^{3+}\right]
$$

The relaxivity can be divided into an inner and an outer sphere term as follows:

$$
r_{1}=r_{1 \text { is }}+r_{1 \mathrm{os}}
$$

The inner sphere term is given in Equation (A3), where $q$ is the number of inner sphere water molecules. ${ }^{1}$

$$
r_{1 i s}=\frac{1}{1000} \times \frac{q}{55.55} \times \frac{1}{T_{1 m}^{H}+\tau_{m}}
$$

The longitudinal relaxation rate of inner sphere protons, $1 / T_{1 m}{ }^{H}$ is expressed by Equation (A4), where $r_{G d H}$ is the effective distance between the electron charge and the ${ }^{1} \mathrm{H}$ nucleus, $\omega_{I}$ is the proton resonance frequency and $\omega_{S}$ is the Larmor frequency of the $\mathrm{Gd}^{3+}$ electron spin. 


$$
\begin{aligned}
& \frac{1}{T_{1 m}^{H}}=\frac{2}{15}\left(\frac{\mu_{0}}{4 \pi}\right)^{2} \frac{\hbar^{2} \gamma_{I}^{2} \gamma_{S}^{2}}{r_{G d H}^{6}} S(S+1) \times\left[3 J\left(\omega_{I} ; \tau_{d 1}\right)+7 J\left(\omega_{S} ; \tau_{d 2}\right)\right] \\
& \frac{1}{\tau_{d i}}=\frac{1}{\tau_{m}}+\frac{1}{\tau_{R H}}+\frac{1}{T_{i e}} \quad \text { for } i=1,2
\end{aligned}
$$

where $\tau_{\mathrm{RH}}$ is the rotational correlation time of the $\mathrm{Gd}-\mathrm{H}_{\mathrm{water}}$ vector.

For small molecular weight chelates (fast rotation), the spectral density function is expressed as in Equation (A6).

$$
J(\omega ; \tau)=\left(\frac{\tau}{1+\omega^{2} \tau^{2}}\right)
$$

For slowly rotating species, the spectral density functions are described the Lipari-Szabo approach. ${ }^{2}$ In this model we distinguish two statistically independent motions; a rapid local motion with a correlation time $\tau_{l}$ and a slower global motion with a correlation time $\tau_{g}$. Supposing the global molecular reorientation is isotropic, the relevant spectral density functions are expressed as in Equations (A7-A11), where the general order parameter $S^{2}$ describes the degree of spatial restriction of the local motion. If the local motion is isotropic, $\mathrm{S}^{2}=0$; if the rotational dynamics is only 
governed by the global motion, $S^{2}=1$.

$$
J\left(\omega_{I} ; \tau_{d 1}\right)=\left(\frac{S^{2} \tau_{d 1 g}}{1+\omega_{I}^{2} \tau_{d 1 g}^{2}}+\frac{\left(1-S^{2}\right) \tau_{d 1}}{1+\omega_{I}^{2} \tau_{d 1}^{2}}\right)
$$

$$
J\left(\omega_{S} ; \tau_{d 2}\right)=\left(\frac{S^{2} \tau_{d 2 g}}{1+\omega_{S}^{2} \tau_{d 2 g}^{2}}+\frac{\left(1-S^{2}\right) \tau_{d 2}}{1+\omega_{S}^{2} \tau_{d 2}^{2}}\right)
$$

$$
\begin{aligned}
& \frac{1}{\tau_{d i g}}=\frac{1}{\tau_{m}}+\frac{1}{\tau_{g}}+\frac{1}{T_{i e}} \quad i=1,2 \\
& \frac{1}{\tau}=\frac{1}{\tau_{g}}+\frac{1}{\tau_{l}}
\end{aligned}
$$


$J_{i}\left(\omega_{I}\right)=\left(\frac{S^{2} \tau_{g}}{1+i^{2} \omega_{I}^{2} \tau_{g}^{2}}+\frac{\left(1-S^{2}\right) \tau}{1+i^{2} \omega_{I}^{2} \tau^{2}}\right) \quad i=1,2$

The rotational correlation time, $\tau_{\mathrm{RH}}$ is assumed to have simple exponential temperature dependence with an $E_{\mathrm{R}}$ activation energy as given in Equation (A12).

$$
\tau_{R H}=\tau_{R H}^{298} \exp \left[\frac{E_{R}}{R}\left(\frac{1}{T}-\frac{1}{298.15}\right)\right]
$$

The outer-sphere contribution can be described by Equations (A13 and A14) where $N_{A}$ is the Avogadro constant, and $J_{o s}$ is its associated spectral density function as given by Equation (A14). . $^{3}$

$$
\mathrm{r}_{1 \mathrm{os}}=\frac{32 \mathrm{~N}_{\mathrm{A}} \pi}{405}\left(\frac{\mu_{0}}{4 \pi}\right)^{2} \frac{\hbar^{2} \gamma_{\mathrm{S}}^{2} \gamma_{\mathrm{I}}^{2}}{\mathrm{a}_{\mathrm{GdH}} \mathrm{D}_{\mathrm{GdH}}} \mathrm{S}(\mathrm{S}+1)\left[3 \mathrm{~J}_{\mathrm{os}}\left(\omega_{\mathrm{I}}, \mathrm{T}_{\mathrm{le}}\right)+7 \mathrm{~J}_{\mathrm{os}}\left(\omega_{\mathrm{S}}, \mathrm{T}_{2 \mathrm{e}}\right)\right]
$$




$$
\mathrm{J}_{\mathrm{os}}\left(\omega, \mathrm{T}_{\mathrm{je}}\right)=\operatorname{Re}\left[\frac{1+14\left(\mathrm{i} \omega \tau_{\mathrm{GdH}}+\frac{\tau_{\mathrm{GdH}}}{\mathrm{T}_{\mathrm{je}}}\right)^{1 / 2}}{1+\left(i \omega \tau_{\mathrm{GdH}}+\frac{\tau_{\mathrm{GdH}}}{\mathrm{T}_{\mathrm{je}}}\right)^{1 / 2}+49\left(\mathrm{i} \omega \tau_{\mathrm{GdH}}+\frac{\tau_{\mathrm{GdH}}}{\mathrm{T}_{\mathrm{je}}}\right)+19\left(\mathrm{i} \omega \tau_{\mathrm{GdH}}+\frac{\tau_{\mathrm{GdH}}}{\mathrm{T}_{\mathrm{je}}}\right)^{3 / 2}}\right]
$$

The longitudinal and transverse electronic relaxation rates, $1 / T_{l e}$ and $1 / T_{2 e}$ are expressed by Equation (A15 and A16), where $\tau_{v}$ is the electronic correlation time for the modulation of the zero-field-splitting interaction, $E_{v}$ the corresponding activation energy and $\Delta^{2}$ is the mean square zerofield-splitting energy. We assumed a simple exponential dependence of $\tau_{v}$ versus $1 / T$ as written in Equation (A17)

$$
\begin{aligned}
& \left(\frac{1}{T_{1 e}}\right)^{Z F S}=\frac{1}{25} \Delta^{2} \tau_{v}\{4 S(S+1)-3\}\left(\frac{1}{1+\omega_{S}^{2} \tau_{v}^{2}}+\frac{4}{1+4 \omega_{S}^{2} \tau_{v}^{2}}\right) \\
& \left(\frac{1}{T_{2 e}}\right)^{Z F S}=\Delta^{2} \tau_{v}\left(\frac{5.26}{1+0.372 \omega_{S}^{2} \tau_{v}^{2}}+\frac{7.18}{1+1.24 \omega_{S} \tau_{v}}\right)
\end{aligned}
$$




$$
\tau_{v}=\tau_{v}^{298} \exp \left[\frac{E_{v}}{R}\left(\frac{1}{T}-\frac{1}{298.15}\right)\right]
$$

The diffusion coefficient for the diffusion of a water proton away from a $\mathrm{Gd}^{3+}$ complex, $D_{G d H}$, is assumed to obey an exponential law versus the inverse of the temperature, with activation energy $E_{D G d H}$, as given in Equation (A18). $D_{G d H}^{298}$ is the diffusion coefficient at $298.15 \mathrm{~K}$.

$$
D_{G d H}=D_{G d H}^{298} \exp \left\{\frac{E_{G d H}}{R}\left(\frac{1}{298.15}-\frac{1}{T}\right)\right\}
$$

In the fitting procedure, we have fixed the $r_{\mathrm{GdH}}$ distance to $3.10 \AA$ and the closest approach of the bulk water protons to the $\mathrm{Gd}^{3+}, a_{\mathrm{GdH}}$ to $3.5 \AA^{5}{ }^{5}$

The diffusion constant has been fixed to $26 \times 10^{-10} \mathrm{~m}^{2} / \mathrm{s}$ and its activation energy was fitted $14 \mathrm{~kJ} / \mathrm{mol}$. The hydration number was 1 and the water exchange rate and the water exchange enthalpy were fixed to the values obtained for GdDOTA.

1. Luz, Z.; Meiboom, S. Proton Relaxation in Dilute Solutions of Cobalt(II) and Nickel(II) Ions in Methanol and the Rate of Methanol Exchange of the Solvation Sphere. J. Chem. Phys. 1964, 40 (9), 2686-2692 DOI: 10.1063/1.1725581.

2. Dunand, F. A.; Tóth, É; Hollister, R.; Merbach, A. E. Lipari-Szabo approach as a tool for the analysis of macromolecular gadolinium(III)-based MRI contrast agents illustrated by the [Gd(EGTA-BA-(CH2)12)]nn+ polymer. JBIC, J. Biol. Inorg. Chem. 2001, 6 (3), 247-255 DOI: 10.1007/s007750000193.

3. Freed, J. H. Dynamic effects of pair correlation functions on spin relaxation by translational diffusion in liquids. II. Finite jumps and independent T1 processes. J. Chem. Phys. 1978, 68 (9), 4034-4037 DOI: 10.1063/1.436302.

4. Koenig, S. H.; Brown, R. D.; Spiller, M.; Chakrabarti, B.; Pande, A. Intermolecular protein interactions in solutions of calf lens alpha-crystallin. Results from 1/T1 nuclear magnetic relaxation dispersion profiles. Biophys. J. 1992, 61 (3), 776-785 DOI: https://doi.org/10.1016/S0006-3495(92)81882-9.

5. $\quad$ Caravan, P.; Ellison, J. J.; McMurry, T. J.; Lauffer, R. B. Gadolinium(III) Chelates as MRI Contrast Agents: Structure, Dynamics, and Applications. Chem. Rev. 1999, 99 (9), 2293-2352 DOI: 10.1021/cr980440x. 